\title{
Editorial
}

\section{Moving to the bed}

$\mathrm{O}$ ver $99.8 \%$ of the Antarctic continent is ice-covered (Burton-Johnson et al. 2016). For much of the 20th century and early 21 st century almost all research in Antarctica took place on the $0.18 \%$ of ice-free terrain or on the ice sheet surface. With some notable exceptions such as the Caltech glaciology and geophysics group of the 1980s (e.g. Engelhart et al. 1990), subglacial access has been rare.

More recently there has been an increased recognition in the importance of the subglacial environment and a concomitant drive to develop subglacial access technologies (Kennicutt et al. 2015, 2016). A range of science disciplines have converged on the need to gain access to the bed. The recognition of subglacial lakes with potential records of long-term ice sheet history and extremophile organisms (e.g. Kapitsa et al. 1996), along with the subsequent recognition of active hydrological networks (Wingham et al. 2006), and what may be an active ecosystem with significant carbon reservoir, have driven several projects from US, UK and Russia to penetrate beyond basal ice and into lakes or the bed, not all of which have yet been successful.

The prospect of regular bed access raised environmental concerns: given the likely hydrological connectivity then any introduced contamination could spread beyond the access point. Fortunately, the community interested in subglacial aquatic environments have collaborated with environmental scientists and policymakers to develop a framework for subglacial access including standards for cleanliness (National Academy of Sciences 2007, SCAR 2011). A critical difference has emerged between subglacial access in those areas frozen to the bed, where there is no hydrological connectivity, and thawed areas where the potential for contamination is higher, especially in upstream areas.

Other scientific disciplines are increasingly interested in bed access: geologists and geophysicists are currently testing drill technologies that will allow sampling of deep drill core to address hypotheses of the geological make-up of Antarctica. Moreover, they will be used to investigate physical properties such as geothermal heat flux, which is a key boundary condition for ice sheet models. Glacial geologists in the UK, US and China are also using early prototypes of drills to sample bedrock for surface exposure dating that will allow testing of hypotheses of past ice sheet collapse. In recent months a major UK subglacial access operation has successfully reached the bed of the Rutford ice stream and sampled material and instrumented the bed and access hole in order to understand ice stream basal conditions.

From this burgeoning activity a number of key themes have emerged. Firstly, the need for cleanliness protocols and oversight by the Antarctic Treaty. Such protocols for cleanliness of access holes have been developed but enforcement of these and providing regulation for sensors and instrumentation left in situ still remains a challenge, as it does in other areas of Antarctic science. A second theme is that many access technologies require either significant oversnow traverse or heavy airlift capability to transport large drill strings, likely driving further international co-operation. Third, the development of technologies requires significant investment in engineering expertise to minimise weight and logistic burden (e.g. for the development of lightweight, Twin-Otter portable subglacial access drills), and to develop instrumentation that can be deployed in the harsh subglacial environment.

The increased scientific drivers for bed access will see a marked increase in drilling projects in coming years. The challenges for the community are to ensure cleanliness protocols and standards are upheld; that the maximum multi-disciplinary use of expensive access holes is encouraged; and that there is international co-operation on the most effective and cleanest access, sampling and instrumentation technologies.

\section{References}

Burton-Johnson, A., Black, M., Fretwell, P.T. \& Kaluza-Gilbert, J. 2016. An automated methodology for differentiating rock from snow, clouds and sea in Antarctica from Landsat 8 imagery: a new rock outcrop map and area estimation for the entire Antarctic continent. The Cryosphere, 10, 10.5194/tc-10-1665-2016.

Engelhart, H., Humphrey, N., Kamb, B. \& Fahnestock, M. 1990. Physical conditions at the base of a fast moving Antarctic ice stream. Science, 248, 10.1126/science.248.4951.57.

Kapitsa, A., Ridley, J.K., De Q. Robin, G., Siegert, M.J. \& Zotikov, I.A. 1996. A large deep freshwater lake beneath the ice of central East Antarctica. Nature, 381, 684-686.

Kennicutt, M., et al. 2015. A roadmap for Antarctic and Southern Ocean science for the next two decades and beyond. Antarctic Science, 27, $10.1017 /$ S0954102014000674

Kennicutt, M., et al. 2016. Delivering 21st century Antarctic and Southern Ocean science. Antarctic Science, 28, 10.1017/S0954102016000481. 
National Academy of Sciences. 2007. Exploration of Antarctic subglacial aquatic environments: environmental and scientific stewardship. Washington, DC: NAS.

SCAR. 2011. Available online at: https:/www.scar.org/scar-library/search/policy/codes-of-conduct/3409-code-of-conduct-for-the-explorationand-research-of-subglacial-aquatic-environments/

Wingham, D., Siegert, M., ShePherd, A. \& Muir, A. 2006. Rapid discharge connects Antarctic subglacial lakes. Nature, 440, $1033-1036$.

Michael J. Bentley Dept of Geography, Durham University, UK 